\title{
Colorectal Tubulovillous Adenoma
}

National Cancer Institute

\section{Source}

National Cancer Institute. Colorectal Tubulovillous Adenoma. NCI Thesaurus. Code C5675.

A neoplasm that arises from the glandular epithelium of the colonic and rectal mucosa. It is characterized by tubular and villous architectural patterns. The neoplastic glandular cells have dysplastic features. 